\title{
Hippocampal lesions impair rats' performance of a nonspatial matching-to-sample task
}

\author{
JOYCE A. JAGIELO, ARTHUR J. NONNEMAN, \\ WALTER L. ISAAC, and PAMELA A. JACKSON-SMITH \\ University of Kentucky, Lexington, Kentucky
}

\begin{abstract}
In the present study, we attempted to develop a nonspatial delayed match-to-sample task that would aid in assessing the role of the hippocampus in memory. It is difficult to compare directly the results of many past studies of hippocampal function because studies using different species often use very different tasks to assess the same theoretical constructs. Rodent studies typically have used spatial tasks, such as the radial arm maze, with or without delays, whereas primate studies typically have used match-to-sample (MTS) tasks. In the present study, we examined the performance of hippocampal-lesioned rats on nonspatial simultaneous matching-to-sample (SMTS) and delayed matching-to-sample (DMTS) in a cross maze. Postoperatively, the hippocampal-lesioned subjects were unable to reacquire the SMTS task they had learned preoperatively. The results suggest that this approach may provide a useful tool for probing the role of the hippocampus in memory, and that the configural relationships between stimuli and events or the conditional nature of a learning/memory task may be especially important aspects for determining the impact of hippocampal damage.
\end{abstract}

The major purpose of this study was to develop a nonspatial matching-to-sample (MTS) task that could aid the assessment of hippocampal involvement in memory processes of the rat.

The role of the hippocampal system in animal memory has been investigated for many years in an attempt to provide a model for the human amnesic syndrome (e.g., Gaffan, 1974, 1977; Squire \& Cohen, 1983; Weiskrantz $\&$ Warrington, 1975). Several theorists have attempted to explain the effect of hippocampal lesions on various memory tasks. O'Keefe and Nadel (1979) proposed a spatial mapping function of the hippocampus, and there is substantial evidence to indicate that hippocampal-system lesions disrupt performance of spatial tasks in rats, monkeys, and humans (Gaffan, 1977; Jones \& Mishkin, 1972; O'Keefe \& Nadel, 1979; Olton, Becker, \& Handelmann, 1979; Smith \& Milner, 1981). There is, however, evidence that hippocampal lesions also result in deficits in performance of nonspatial tasks (Meck, Church, \& Olton, 1984; Olton et al., 1979; Olton \& Feustle, 1981; Ross, Orr, Holland, \& Berger, 1984).

Olton et al. (1979) have suggested a much different function of the hippocampus. Following the distinction

This research was funded in part by grants from Sigma Xi and the University of Kentucky Graduate School (J.A.J.) and by Grants BRSG 2-S07-RR07114 and NIMH MH27345 (A.J.N.). The authors would like to thank Raymond P. Kesner, Norman E. Spear, James S. Miller, and two anonymous reviewers for their helpful comments on an earlier draft of the manuscript, and Lizeth Grijalva for her help in running the animals. Reprint requests may be sent to the first author at the Center for Developmental Psychobiology, Departmenî of Psychology, SUNY Binghamton, Binghamton, NY 13901.

-Accepted by previous editor, Lynn Nadel made by Honig (e.g., 1978, 1984) between working and reference memory in the pigeon literature, Olton et al. proposed the hippocampus to be important in working memory but not in reference memory. Typically, working memory is defined as the memory, during a delay, for a previous event of that trial which will allow for correct behavior at the end of the delay. For example, using a three-key intelligence panel in a delayed matching-tosample (DMTS) task, a pigeon is presented with the center (sample) key illuminated green. Following sample presentation, all three keys are dark for a specified delay inter$\mathrm{val}$. At the end of the delay, the two side (comparison) keys are illuminated-one red, the other green. The pigeon must respond to the green (matching) comparison key in order for reinforcement to occur. Memory for the sample during the delay involves working memory. Working memory involves information that is applicable only within a trial and is reset between trials. Reference memory is the long-term memory for the rules of the task - that is, information that is applicable across trials (see Honig, 1978, 1984; Maki, 1984; Roitblat, 1984). In the above case with the pigeon, reference memory would include the memory that keys need to be pecked, that pecking a comparison key can lead to reinforcement, and the rule "if the sample is green, then peck the green comparison."

Some support for the working-memory hypothesis of hippocampal function has come from studies that have demonstrated a disruption of working memory in certain spatial and nonspatial tasks (Jarrard, 1980, 1983; Olton et al., 1979). For example, using a 17-arm radial maze, Olton et al. baited eight of the arms and left the rest of the arms (consistently) unbaited. The rats' task was to ob- 
tain each of the reinforcers in an efficient manner. This meant not entering the never-baited arms, and not reentering the arms from which a reinforcer had already been obtained. According to Olton et al., the ability to avoid never-baited arms required reference memory, whereas not reentering previously visited arms required working memory. Following acquisition of this task, rats were given fimbria-fornix lesions. The rats rarely entered the never-baited arms (indicating to Olton et al. an intact reference memory) but often reentered previously chosen arms, indicating a working-memory deficit.

The radial maze evidence that the hippocampus affects working memory selectively is indirect. This task does not fully separate working- and reference-memory predictions. It does not allow a direct comparison between a task in which working memory is required (use of a delay) and the same task in which working memory is not required (no delay). Furthermore, the reference-memory rules of the radial arm maze task include: "Never enter nonbaited arms"' and "Never reenter an arm from which the reinforcer has been obtained." Although the data of Olton et al. (1979) provide evidence that the first rule is remembered, it is difficult to disentangle memory loss for the second rule from a working-memory deficit. The rats may reenter baited arms from which a reinforcer has been obtained because of a working-memory deficit, a reference-memory deficit, or both.

Tasks more typically used with studies of working and reference memory in most species are the simultaneous matching-to-sample (SMTS) and the DMTS tasks. These tasks are valuable because working and reference memories can be assessed directly. In the SMTS task, the problem of matching the sample with the correct comparison does not require working memory, since there is no delay. Comparison stimuli are presented while the sample is still present. Once the task is learned, it can be solved on the basis of reference memory alone. In pigeons, it would be the rule, "If the sample is green, peck the green comparison," and so forth. The DMTS task does involve delay, and therefore, working memory. The working-memory hypothesis of hippocampal function would predict that rats with hippocampal lesions should do well on the SMTS task, but show a deficit on the DMTS task.

Another recent hypothesis of hippocampal function, Kesner's (1986) attribute theory, states that the hippocampus is important for both spatial and temporal aspects of any given task. The attribute theory predicts that when spatial and temporal memories are both important in the task (e.g., a delayed alternation task), hippocampal-lesioned animals will show a significant deficit. When either spatial or temporal aspects (but not both) are important, the deficit should be more modest, or perhaps nonexistent. When neither spatial nor temporal aspects are important, no deficit should be seen. According to this theory, hippocampal rats should show no deficit on the SMTS task (no spatial or temporal aspects) but a modest deficit on the DMTS task (temporal aspect present).
Yet another recent theory of hippocampal function (Sutherland \& Rudy, 1989) asserts that the hippocampal formation provides the neural basis for the storage of configural associations between events. According to this view, the hippocampus is not necessary for the formation or retention of associations between elementary stimulus events, and hippocampal damage would not impair performance on tasks that can be learned on the basis of changes in the strength of associations between elementary stimulus events (see Rescorla \& Wagner, 1972). By emphasizing the importance of the hippocampal formation for relational operations, this new theory makes many of the same predictions as Hirsh $(1974,1980)$, who emphasized context and conditional operations.

In the present study, rats were trained preoperatively on nonspatial SMTS and DMTS tasks in a cross maze. They were then subjected to lesions of the hippocampus or occipital cortex or to sham lesions, and retested on these tasks. Because of the conditional nature of these tasks and the fact that they cannot easily be solved on the basis of simple associations between elemental stimulus events, both Hirsh (1974, 1980) and Sutherland and Rudy (1989) would predict deficits on both the delay and the nondelay variants of this MTS task.

\section{METHOD}

\section{Subjects}

The subjects were 18 male Sprague-Dawley rats, approximately 90 days old at the start of the experiment. They were individually housed and allowed free access to water. The rats were maintained on a 23-h food-deprivation schedule, with 1-h access to wet mash. At the end of the hour, the mash was removed and each rat was given a chocolate chip. The rats were handled a minimum of twice a week for approximately $15 \mathrm{~min}$ each time during the entire experiment. The colony room was maintained on a 12 -h light/12-h dark cycle, with light onset at $0700 \mathrm{~h}$. All testing was conducted during the light cycle. Data from 8 subjects were not included in the analyses. One rat failed to learn the initial (preoperative) DMTS task, 1 developed intestinal tumors, and 6 did not survive surgery. This resulted in 5 rats in the hippocampal-lesion group, 3 in the sham-operate group, and 2 in the cortical control group. Only the data from these 10 rats are reported in the analyses.

\section{Apparatus}

The cross maze consisted of four equal-size alleys (arms) attached to a $13-\mathrm{cm}^{2}$ central choice area. Each alley measured (inside) $73.5 \mathrm{~cm}$ long, $13 \mathrm{~cm}$ wide, and $13 \mathrm{~cm}$ high. Two adjacent alleys were black on the inside, the other two white. The outside of the maze and the central choice area were gray. At the end of each arm was a concealed food well. Guillotine doors were located at each of the four points where the alleys join the central choice area.

\section{Tasks}

Simultaneous matching-to-sample task. On a given SMTS trial, one of the four arms served as the "sample" alley, and the two arms perpendicular to the sample alley served as the "comparison" alleys. The alley immediately across from the sample alley was not in use on any given trial, and was blocked by a door that matched the sample alley in color. This was done to create as complete an analogy as possible to the SMTS task used with primates and pigeons. The rat was required to run down the sample alley to the central choice area and choose the comparison alley that was the same color as the sample alley. Doors to the sample and compari- 
son alleys remained open until the rat made a choice response. Choice was defined as all four of the subject's feet in a comparison alley. When the choice was made, the door to the alley selected was lowered, and the rat was allowed 10-sec access to wet mash for a correct choice, or was confined to the arm for $10 \mathrm{sec}$ when an incorrect choice was made. A 10 -sec intertrial interval (ITI) separated the trials and was spent in an ITI box (a deep wooden holding chamber). Each arm of the maze was used as the sample alley three times a day, for a total of 12 trials per day. The order of the sample alleys was randomly determined, with the constraint that no more than three of a color or three of the same "correct-choice" direction (right/left) were to occur consecutively. The entire maze was rotated daily to further prevent the use of spatial cues. In order to prevent the odor of the wet mash in the baited arm from influencing the rat's choice, dishes of wet mash were placed outside of the maze on each side of the sample alley where the alley joined the central choice area.

Delayed matching-to-sample task. This task was similar to the SMTS task described above, with the following exceptions: (1) the doors of the comparison alleys, in addition to that of the unused alley, were lowered from the start of the trial; (2) all doors were gray; (3) the door to the sample alley was also lowered as soon as the rat reached the central area, thus confining the rat; (4) the rat was confined for a 0-, 5-, or 10-sec delay. Each delay interval was paired with each alley. Delays were presented in a random order, with the constraint that no more than three of the same delay occurred in a row; and (5) at the end of the delay, the doors to the comparison alleys were opened and the rat was allowed to make a choice response.

Simultaneous nonmatching-to-sample task. The procedure for the nonmatching task was identical to the SMTS task, with the exception that the rat was required to choose the alley that did not match the color of the sample alley.

\section{General Procedure}

The rats were placed on a 23-h food-deprivation schedule at the start of the experiment. For 5 days, the rats were allowed to adapt to the maze. During adaptation, the rats were started twice in each arm of the maze, for a total of eight trials. For the first 3 days only, reinforcement was available at the ends of both choice arms. Passive force (blocking the nonmatching arm) was used, when necessary, to ensure that each rat experienced the reinforcer in buth arm colors at least three times a day. Day 4 was similar to Days $1-3$, except that the reinforcer was available only in the matching choice arm. On Day 5 of adaptation, no passive force was used. Instead, the rats were run on each trial until they made a matching response. The rats were then placed on the SMTS task and run 12 trials a day until they reached the criterion of 3 consecutive days at $90 \%$ (11 of 12 trials) correct or above. Criterion and number of trials per day were the same for all phases of the experiment (except adaptation). The rats were then placed immediately (next day) on the DMTS task with delays of 0,5 , and $10 \mathrm{sec}$ until they reached criterion. At this point, the rats were assigned to one of three surgical groups: hippocampal lesion, cortical control, or sham operates. The groups were equated, as much as possible, on number of sessions to reach criterion on the DMTS task. The rats were off the task for 1 day between reaching criterion and surgery.

Following surgery, the animals were given a 3-week recovery period, during which they had 24-h access to wet mash and were not run in the maze. For all but the first 2 days postsurgery, the animals were handled for a minimum of $1 \mathrm{~h}$ per day during the recovery period. Following recovery, the rats were returned to the SMTS task until criterial performance was reacquired. If the SMTS task was reacquired, the rat was returned to the DMTS task. Finally, all rats were run on a simultaneous nonmatching task beginning the day after completion of their previous task.
Surgery

Hippocampal-lesioned rats were anesthetized with chloral hydrate ( $350 \mathrm{mg} / \mathrm{kg}$, i.p.). The scalp was incised on the midline, and the periosteal fascia was scraped to the side. The bone overlying the hippocampus was removed by a dental burr and rongeurs. Bilateral electrolytic lesions of the hippocampus were performed using a monopolar stainless steel electrode insulated with Epoxylite, except for $0.5 \mathrm{~mm}$ at the tip. The coordinates for stereotaxis placement (Pellegrino \& Cushman, 1967) and current parameters were as follows: $A P-2.6 \mathrm{~mm}, \mathrm{~L} \pm 2.0 \mathrm{~mm}, \mathrm{~V}-3.0 \mathrm{~mm}, 1.5 \mathrm{~mA}$ for $30 \mathrm{sec}$; AP $-3.5 \mathrm{~mm}, \mathrm{~L} \pm 5.0 \mathrm{~mm}, \mathrm{~V}-5.0 \mathrm{~mm}, 1.5 \mathrm{~mA}$ for $45 \mathrm{sec}$; AP $-5.0 \mathrm{~mm}, \mathrm{~L} \pm 5.0 \mathrm{~mm}, \mathrm{~V}-6.5 \mathrm{~mm}, 1.5 \mathrm{~mA}$ for $45 \mathrm{sec}$; and AP $-5.0 \mathrm{~mm}, \mathrm{~L} \pm 4.0 \mathrm{~mm}, \mathrm{~V}-3.0 \mathrm{~mm}, 1.5 \mathrm{~mA}$ for $45 \mathrm{sec}$. The incisor bar was positioned at $+1.0 \mathrm{~mm}$. Bregma served as the reference point for $\mathrm{AP}$ and $\mathrm{L}$ coordinates. Depth coordinates were measured from the top of the cortex. Following surgery, all subjects received a 50,000-unit dose of Combiotic in the hind-leg muscle.

The cortical control group was treated similarly to the hippocampal-lesion group, except that the electrode was lowered to (but not through) the hippocampus and no current was passed. The sham group received only the anesthesia, the scalp incision, and the Combiotic.

\section{Histology}

Upon completion of all testing, the rats were injected with an overdose of chloral hydrate $(600 \mathrm{mg} / \mathrm{kg}$, i.p.) and exposed to chloroform until breathing ceased. The rats were then perfused with normal saline followed by $10 \%$ formalin in saline. Brains were removed and fixed in a solution of $30 \%$ sucrose and $10 \%$ formalin for 3 days. They were then rinsed with water, blocked in the stereotaxic plane (discarding the frontal poles and cerebellum), and cut on a freezing microtome at $40 \mu \mathrm{m}$. Every 10 th section through the lesion was mounted on glass slides and stained with cresyl-violet acetate. These slides were then examined on a microprojector and lesions were reconstracted. (See Figure 1 for the minimum and maximum lesion sizes for the cortical control group, and Figure 2 for the minimum and maximum lesion sizes for the hippocampal-lesion group.)

\section{RESULTS}

\section{Acquisition of the SMTS Task (Presurgery)}

All animals acquired the SMTS task. A one-way ANOVA of the data for the 10 rats completing all test phases indicated no significant $(p<.05)$ differences between the groups on number of sessions to reach criterion on the SMTS task. A mean of $\mathbf{4 5 . 5}$ sessions was required to master this task.

A repeated measures ANOVA was performed on the mean number of errors per group across blocks of four sessions. Blocks of four sessions were chosen so that each block would contain each of the maze rotations. The analysis showed only a significant decrease in number of errors across blocks $[F(11,77)=14.308, p<.01]$. There were no significant group or interaction (group $\times$ block) effects.

\section{Acquisition of the DMTS Task (Presurgery)}

The mean number of sessions to criterion was 78.3 $( \pm 18.45)$ for the rats in the sham-operate group, 88.5 $( \pm 10.5)$ for those in the cortical control group, and 80.4 


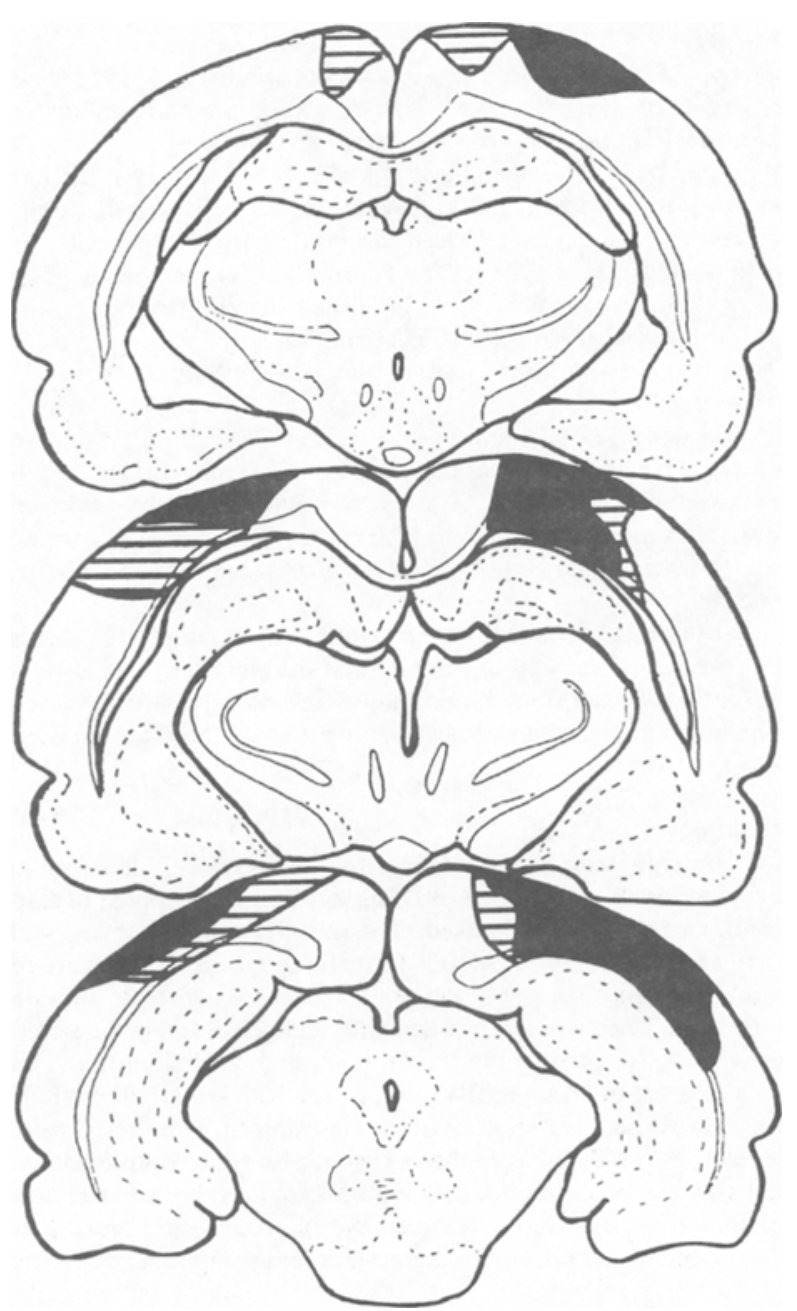

Figure 1. Smallest (black) and largest (striated) lesions in the cortical control group.

( \pm 16.11$)$ for the animals in the hippocampal-lesion group. A one-way ANOVA indicated no significant difference between the groups.

A repeated measures ANOVA on mean number of errors across blocks of four sessions yielded only a significant decrease in errors across blocks $[F(23,161)=7.846$, $p<.01$, with no significant group or interaction effects. Because of the stringent criterion, all 10 rats were performing well on all delay intervals at the end of testing. However, a significant influence of delay interval was still evident in the last 4-day block before surgery, with mean percent-correct performances of $92 \%, 88 \%$, and $83 \%$ at $0-, 5-$, and 10-sec delays, respectively. This resulted in a significant difference between 0 - versus 10 -sec delays $[t(9)=2.34, p<.05]$ but not 0 - versus $5-[t(9)=0.55]$ or 5 - versus 10 -sec delays $[t(9)=1.50]$.

\section{Reacquisition of the SMTS Task (Postsurgery)}

The sham and cortical control operates reacquired the SMTS task. The sham group required a mean of 24.7 ses- sions and the cortical control group a mean of 25.5 sessions to reach criterion. The maximum number of sessions it took any of these rats to reacquire the task was 30. After twice the number of sessions of the worst control rat (60 sessions), the hippocampal animals showed no signs of reacquiring the task. At this point, the hippocampal rats were switched to the simultaneous nonmatching-to-sample task and given a score of 60 sessions for the SMTS task. It should be noted that the 60-session limit exceeded the number of sessions required by any of the hippocampal rats to acquire the task preoperatively. A one-way ANOVA on sessions to reach criterion yielded a significant group effect $[F(2,7)=77.042$, $p<.01]$. A post hoc Newman-Keuls test $(p<.05)$ indicated that the performance of the hippocampal operates was significantly worse than that of the cortical controls and sham operates, but that the cortical controls and sham operates did not differ from each other.

A repeated measures analysis of number of errors across blocks of four sessions indicated a significant group ef-

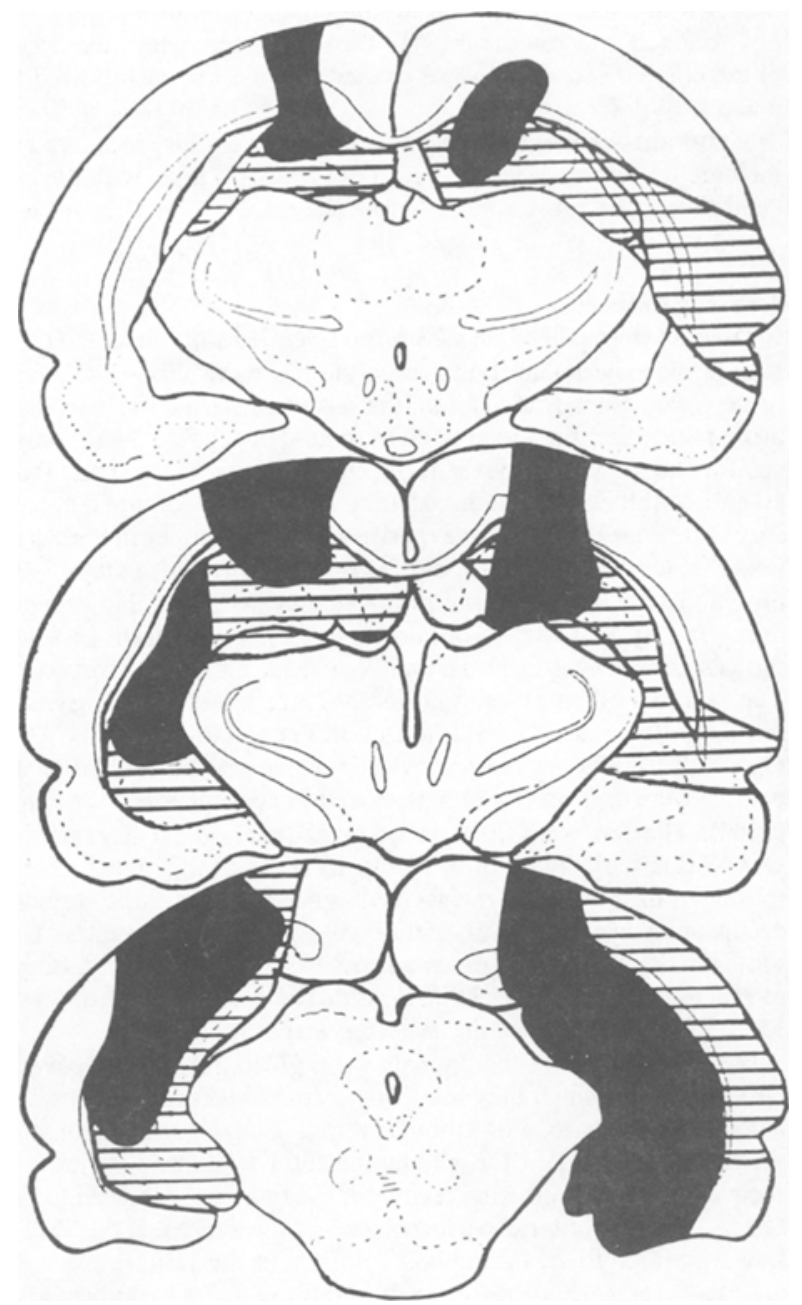

Figure 2. Smallest (black) and largest (striated) lesions in the hippocampal group. 
fect $[F(2,7)=20.763, p<.01]$, a significant block effect $[F(7,49)=10.884, p<.01]$, and a significant interaction effect $[F(14,49)=2.039, p<.05]$. Newman-Keuls tests indicated that the hippocampal operates failed to reduce errors over blocks, whereas both control groups showed a significant improvement over blocks. The control groups did not differ from each other in the number of errors across blocks (see Figure 3 ).

\section{Reacquisition of the DMTS Task}

Since only the sham and cortical control groups reacquired the SMTS task, only these two groups were transferred to the DMTS task. The sham group required a mean of 44.3 sessions to reacquire the task, whereas the cortical control group required a mean of 28.5 sessions. A one-way ANOVA of sessions to criterion indicated no significant difference between groups. A repeated measures ANOVA on the number of errors across blocks of four sessions showed no significant group effect, but did show a significant block effect $[F(7,21)=2.889$, $p<.05]$ and a significant interaction effect $[F(7,21)=$ $2.585, p<.05]$.

As in preoperative acquisition of DMTS, delay interval significantly influenced the performance of the sham and cortical control operates on reacquisition of this task. One rat reached criterion-level performance on Session 15 . Therefore, only the first 12 sessions (three blocks) were subjected to analysis of the delay effect. Mean percent-correct performance for 0-, 5-, and 10-sec delays was $84 \%, 73 \%$, and $73 \%$, respectively. The performance difference between 0 - and 10-sec delays was statistically significant $[t(4)=3.04, p<.05]$, whereas the difference between 0 - and 5 -sec delay intervals was not $[t(4)=1.92]$. The fact that performance on the 5and 10-sec delay intervals did not differ may indicate that the increase from 5 to $10 \mathrm{sec}$ may not add significantly to the demand on the rats' memory. Thus, longer delays may be advisable in future experiments with this task.

\section{Nonmatching-to-Sample Task (Postsurgery)}

The sham group required a mean of 50.3 sessions and the cortical group a mean of 81.0 sessions to acquire the task. After a number of sessions equal to that of the worst control animal (85 sessions), the hippocampal-lesioned

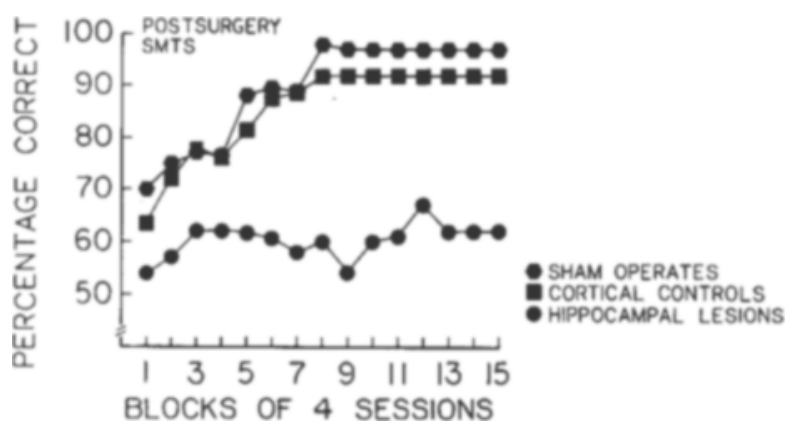

Figure 3. Mean percentage correct during reacquisition of the simultaneous matching-to-sample task (postoperatively).

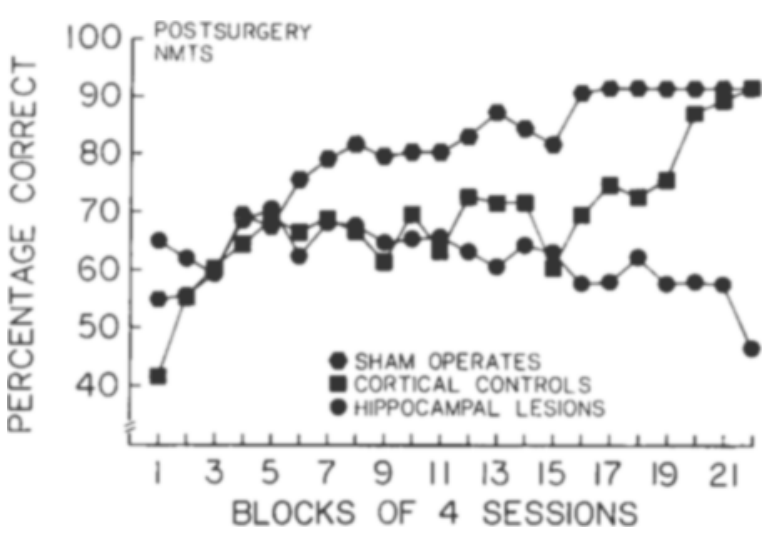

Figure 4. Mean percentage correct during postoperative acquisition of the simultaneous nonmatching-to-sample task.

rats showed no signs of learning the task, and testing was terminated. A repeated measures ANOVA on the number of errors across blocks of four sessions indicated a significant group effect $[F(2,7)=7.509, p<.05]$, a significant block effect $[F(15,105)=7.237, p<.01]$, and a significant interaction effect $[F(30,105)=3.148$, $p<.01$ ] (see Figure 4).

Newman-Keuls tests indicated no significant differences between the hippocampal operates and the sham operates prior to Block 8, but a consistent superiority of the shams across Blocks 8-16. (Analyses could be done only through Block 16 because by that point the sham operates had acquired the task.) Although the cortical controls did not differ from the hippocampals through Block 16, they did go on to acquire the task by Block 22. By the end of Block 22, hippocampal operates showed no signs of acquiring the task.

\section{DISCUSSION}

Although hippocampal-lesioned rats are clearly capable of solving simultaneous brightness discriminations (Bauer, 1974; Kimble, 1963; Silviera \& Kimble, 1968; Winocur \& Gilbert, 1984), in the present study, the hippocampal rats were unable to reacquire the black-white MTS task even when the sample and comparison cues were present simultaneously. Nor were they able to acquire postoperatively a simultaneous nonmatching-to-sample (NMTS) version of this task.

These results do not provide support for the workingmemory hypothesis of hippocampal function (Olton et al., 1979). The working-memory hypothesis predicts that animals with hippocampal lesions should show no deficit on the SMTS or NMTS task, because no delay is involved. Both sample and comparison cues are present simultaneously, and therefore working memory is not required. Despite this lack of memory load, hippocampal lesions severely disrupted performance of these tasks.

The inability of hippocampal operates to solve the SMTS and NMTS tasks also suggests some problem for the attribute theory of memory advanced by Kesner 
(1986). The present task was not solvable on the basis of spatial cues, and the subjects need not have used temporal cues, as the sample and comparison could be observed simultaneously. Even if the rats should employ a temporal tagging of events, this theory would predict only a modest deficit, not the profound one observed here.

Thus, these results suggest that the function of the hippocampus is not limited to working memory, nor is it entirely encompassed by spatial and temporal demands of the environment. Clearly, animals with hippocampal lesions do show impaired performance on tasks that incorporate spatial and/or temporal demands (e.g., Gaffan, 1977; Kesner \& DiMattia, 1987; O'Keefe \& Nadel, 1979; Olton et al., 1979). However, the present study shows that even when the task does not present these demands, a severe impairment may be observed.

The present results would also appear to be in opposition to those reported by Aggleton, Hunt, and Rawlins (1986). They reported that extensive aspiration lesions of the hippocampus did not impair rats' performance of a nonspatial, nonmatching Y-maze task, even with delays as long as $60 \mathrm{sec}$. To help understand this apparent discrepancy, it is necessary to note that there are several differences between the nonmatching task used in the present study and the nonmatching tasks used by most other investigators (e.g., Aggleton et al., 1986; Mishkin, Malamut, \& Bachevalier, 1984). In the typical nonmatching task, Stimulus $A$ is presented and reinforced. The animal is then given a choice between Stimulus $A$ and Stimulus B. The animal must choose the new stimulus (B) in order to be reinforced. The animal is then presented with Stimulus B and Stimulus C, and so forth, and must always choose the new stimulus. Typically, a large number of stimuli are used per session (e.g., 40-50), and the stimuli are not repeated during the session, or sometimes not across the entire experiment. This indicates at least four major differences between the present method and the nonmatching task more commonly used with hippocampal animals.

First, it could be argued that the hippocampal rats in the present study failed to learn either the matching or the nonmatching task because of trial-to-trial interference caused by using only two stimuli. It seems unlikely that this is the sole cause of the deficit, though, since an inspection of performance by trial number did not indicate that the performance of the hippocampal-lesioned group worsened as the session continued. If anything, there was a slight improvement in performance across trials within a session. In addition, Olton and Feustle (1981) demonstrated a profound and enduring deficit in postoperative reacquisition of a nonspatial nonmatching-to-sample task by rats with fimbria-fornix lesions. That study involved a four-arm enclosed radial maze in which all four arms were visually and tactually distinctive, but in which the spatial location of the arms was changed between and within trials. Despite this rich array of cues distinguishing the maze arms, the postoperative performance of the rats with fimbria-fornix lesions remained at chance levels throughout 60 sessions of testing.
Second, it is possible that matching and nonmatching tasks are inherently different, and that NMTS tasks are inherently easier for hippocampal rats. But this would not explain the discrepancy between the Aggleton et al. (1986) and the Olton and Feustle (1981) studies, both of which used nonspatial nonmatching-to-sample tasks. Moreover, the hippocampal-lesioned subjects in the present study were equally unable to reacquire the SMTS task and to acquire the nonmatching task. It could be argued that the failure of these hippocampal-lesioned rats to acquire the nonmatching task is due to a negative transfer effect in the present study. Hippocampal-lesioned animals are typically impaired on negative transfer tasks (e.g., see Douglas \& Pribram, 1966). Yet this was not truly a negative transfer situation, because the hippocampal-lesioned animals did not reacquire the SMTS task. In addition, pilot data we have collected suggest that the performance of naive rats trained first on the nonmatching task described in the present study does not differ from that of the rats (in the present study) trained first on the matching task. Although we do not yet know how these naive nonmatching-to-sample rats will perform postoperatively, this provides evidence that normal rats do not differ in rate of acquisition of these two tasks.

A third difference between the Aggleton et al. (1986) and the present study is reinforcement or nonreinforcement, respectively, of the sample. Apparently this is not a critical difference, however, as Raffaelle and Olton (1988), using a symmetrically reinforced matching task analogous to the nonmatching task used by Aggleton et al., reported that rats with fimbria-fornix lesions were unable to reacquire the task they had learned preoperatively.

The final difference, and probably the most critical, is in the conditional nature of the present tasks (Hirsh, 1974, 1980). Whether or not the response to a white arm, for example, was reinforced depended upon the color of the sample arm the rat had just experienced. If the sample arm was white, the response of running down the white comparison arm was reinforced in the matching task and nonreinforced in the nonmatching task. If the sample arm was black, running down the white comparison was not reinforced in the matching task, but was reinforced in the nonmatching task. This differs from Aggleton et al.'s (1986) procedure, which required the animal always to go to the new stimulus for reinforcement. Learning to approach the new stimulus is different from learning a conditional discrimination. The latter requires the animal to learn a particular relationship between the stimuli (cf. Sutherland \& Rudy, 1989), to learn that under certain conditions a particular response is appropriate, while under others it is not. In always approaching the novel stimulus, the same response is appropriate under all circumstances.

Holland (1990) and Ross et al. (1984) have shown that hippocampal lesions disrupt the learning and retention of conditional discriminations, but not the learning or retention of simple associations or nonconditional discriminations, indicating a separate physiological basis for condi- 
tional discrimination learning. Holland has further shown that hippocampal operates, though impaired on conditional discriminations, are unimpaired on very difficult nonconditional discriminations. This suggests for both Holland and the present study that it is not the difficulty of the task but the conditional nature of the task that makes it seemingly impossible for the hippocampal operates to learn.

The fact that hippocampal-lesioned rats may be unable to solve conditional discrimination tasks (but see Davidson \& Jarrard, 1989) is probably responsible for the similarity between the present results and those reported by Raffaelle and Olton (1988). Although our apparatus and procedures differed in many ways (symmetrical vs. nonsymmetrical reinforcement of sample and comparison runs, presence or absence of a delay between sample and comparison cue presentation), both studies used only two stimuli in a conditional, nonspatial task. Neither task could be solved on the basis of "always approach the novel stimulus," but rather the animal had to learn that approaching Stimulus 2 was appropriate only when Stimulus 2 had just been presented, and not when Stimulus 1 had just been presented. It should be noted that this explanation can also account for the results of Olton et al.'s (1979) study. Recall that the rats in that study had no trouble in avoiding never-baited arms, but often reentered previously baited arms. The never-baited arms gave the rats a consistent cue-"always avoid"'-whereas entering the baited arms was conditional upon whether the animal had previously entered the arm on that trial.

As noted above, the presence or absence of an inescapable conditional relationship between the sample and the correct comparison cue probably also accounts for the discrepancy between these two studies and three of the five experiments reported by Aggleton et al. (1986). Their Experiment 3 replicated a well-established finding that hippocampal lesions profoundly impair learning of a conditional two-choice alternation task in the $\mathrm{T}$ maze. Their Experiment 2, which was the most similar in design to the present experiment and to that of Raffaelle and Olton (1988), gave rats a choice between two stimuli in a nonspatial, nonmatching-to-sample task. The cue not chosen on the previous trial was correct on the subsequent trial. Unfortunately, the rats were tested for only 50 trials, and the performance of the control rats did not exceed chance at the end of testing. It should be noted that at least 200 trials were required before performance of the control groups consistently exceeded chance in initial preoperative acquisition of the conditional nonspatial matchingto-sample tasks of Raffaelle and Olton and the present study.

In summary, the results of this study are consistent with earlier reports that hippocampal-system damage disrupts the learning and retention of configural or conditional nonspatial tasks as well as spatial tasks. However, these results also suggest that theories of hippocampal function that are based on distinctions between working and reference memory or between the spatial and temporal aspects of a task may be inadequate in themselves. Hippocampal lesions appear to cause enduring deficits on conditional discrimination tasks even when there is no workingmemory load and even when spatial and temporal cues are irrelevant. The conditional nature of a learning/memory task appears to be at least as important as any other aspect of the task for determining the impact of hippocampal function on that task.

Finally, and perhaps most important, the MTS tasks employed in the present study would appear to offer a technique for the assessment of hippocampal function in rats that is directly analogous to tasks used in memory studies with unoperated pigeons (e.g., Roberts \& Grant, 1976), monkeys (e.g., D'Amato, 1973), and humans (e.g., Sidman \& Tailby, 1982; Sidman et al., 1982).

\section{REFERENCES}

Aggleton, J. P., Hunt, P. R., Rawlins, J. N. P. (1986). The effects of hippocampal lesions upon spatial and nonspatial tests of working memory. Behavioural Brain Research, 19, 133-146.

BAUER, R. H. (1974). Brightness discrimination of pretrained and nonpretrained hippocampal rats reinforced for choosing brighter or dimmer alternatives. Journal of Comparative \& Physiological Psychology, 87, 987-996.

D'Aмкто, M. R. (1973). Delayed matching and short-term memory in monkeys. In G. H. Bower (Ed.), The psychology of learning and motivation: Advances in theory and research (Vol. 7, pp. 227-269). New York: Academic Press.

Davidson, T. L., JARRARD L. E. (1989). Retention of concurrent conditional discriminations in rats with ibotenate lesions of hippocampus. Psychobiology, 17, 49-60.

Douglas, R. J., \&ribram, K. H. (1966). Leaming and limbic lesions. Neuropsychologia, 4, 197-220.

GAFFAN, D. (1974). Recognition impaired and association intact in the memory of monkeys after transection of fomix. Joumal of Comparative \& Physiological Psychology, 86, 1100-1109.

GafFaN, D. (1977). Recognition memory after short retention intervals in fornix-transected monkeys. Quarterly Journal of Experimental Psychology, 29, 577-588.

HIRSH, R. (1974). The hippocampus and contextual retrieval of information from memory: A theory. Behavioral Biology, 12, $421-444$.

HiRsH, R. (1980). The hippocampus, conditional operations, and cognition. Physiological Psychology, 8, 175-182.

Holland, P. (1990). Forms of memory in Pavlovian conditioning. In J. L. McGaugh, N. M. Weinberger, \& G. Lynch (Eds.), Brain organization and memory: Cells, systems and circuits. New York: Oxford University Press.

HonIG, W. K. (1978). Studies of working memory in the pigeon. In S. H. Hulse, H. Fowler, \& W. K. Honig (Eds.), Cognitive processes in animal behavior (pp. 177-248). Hillsdale, NJ: Erlbaum.

HoNIG, W. K. (1984). Contributions of animal memory to the interpretation of animal learning. In H. L. Roitblat, T. G. Bever, \& H. S. Terrace (Eds.), Animal cognition (pp. 29-44). Hillsdale, NJ: Erlbaum.

JARRARD, L. E. (1980). Selective hippocampal lesions and behavior. Physiological Psychology, 8, 198-206.

JARRARD, L. E. (1983). Selective hippocampal lesions and behavior: Effects of kainic acid lesions on performance of place and cue tasks. Behavioral Neuroscience, 97, 873-889.

JoNES, B., \& MisHKIN, M. (1972). Limbic lesions and the problem of stimulus-reinforcement associations. Experimental Neurology, 36, 362-377

KeSNer R. P. (1986). Neurobiological views of memory. In J. Martinez \& R. P. Kesner (Eds.), Learning and memory: A biological view (pp. 399-438). Orlando, FL: Academic Press.

KESNER, R. P., DiMatTia, B. V. (1987). Neurobiology of an attribute model of memory. Progress in Psychobiology \& Physiological Psychology, 12, 207-277.

KumbLe, D. P. (1963). The effects of bilateral hippocampal lesions in 
rats. Journal of Comparative \& Physiological Psychology, 56, 273-283.

MAKI, W. S. (1984). Some problems for a theory of working memory. In H. L. Roitblat, T. G. Bever, \& H. S. Terrace (Eds.), Animal cognition (pp. 117-133). Hillsdale, NJ: Erlbaum.

Meck, W. H., Сhurch, R. M., \& Olton, D. S. (1984). Hippocampus, time and memory. Behavioral Neuroscience, 98, 3-22.

Mishinin, M., Malamut, B., Bachevalier, J. (1984). Memories and habits: Two neural systems. In G. Lynch, J. L. McGaugh, \& N. M. Weinberger (Eds.), Neurobiology of learning and memory (pp. 65-77). New York: Guilford.

O'Keefe, J., \& Nadel, L. (1979). Precis of O'Keefe \& Nadel's: The hippocampus as a cognitive map. Behavioral \& Brain Sciences, 2 , 487-533.

Olton, D. S., Becker, J. T., \& Handelmann, G. E. (1979). Hippocampus, space, and memory. Behavioral \& Brain Sciences, 2, 313-365.

Olton, D. S., \& Feustle, W. A. (1981). Hippocampal function required for nonspatial working memory. Experimental Brain Research, 41, 380-389.

Pellegrino, L. J., \& Cushman, A. J. (1967). A stereotaxic atlas of the rat brain. New York: Appleton-Century-Crofts.

Raffaelle, K. C., \& Olton, D. S. (1988). Hippocampal and amygdaloid involvement in working memory for nonspatial stimuli. $B e$ havioral Neuroscience, 102, 349-355.

Rescorla, R. A., \& Wagner, A. R. (1972). A theory of Pavlovian conditioning: Variations in the effectiveness of reinforcement and nonreinforcement. In A. H. Black \& W. F. Prokasy (Eds.), Classical conditioning: II. Current research and theory (pp. 64-99). New York: Appleton-Century-Crofts.

RoberTs, W. A., \& Grant, D. S. (1976). Studies of short-term memory in the pigeon using the delayed matching-to-sample procedure. In D. L. Medin, W. A. Roberts, \& R. T. Davis (Eds.), Processes of animal memory (pp. 79-112). Hillsdale, NJ: Erlbaum.
RoITBLAT, H. L. (1984). Representations in pigeon working memory. In H. L. Roitblat, T. G. Bever, \& H. S. Terrace (Eds.), Animal cognition (pp. 79-97). Hillsdale, NJ: Erlbaum.

Ross, R. T., Orr, W. B., Holland, P. C., \& Berger, T. W. (1984). Hippocampectomy disrupts acquisition and retention of learned conditional responding. Behavioral Neuroscience, 98, 211-225.

Sidman, M., Rauzin, R., Lazar, R., Cunningham, S., Tailby, W., \& Carrigan, P. (1982). A search for symmetry in the conditional discrimination of rhesus monkeys, baboons, and children. Joumal of the Experimental Analysis of Behavior, 37, 23-44.

Sidman, M., TAILBY, W. (1982). Conditional discrimination versus match-to-sample: An expansion of the testing paradigm. Journal of the Experimental Analysis of Behavior, 37, 5-22.

Silviera, J. C., \& Kimble, D. P. (1968). Brightness discrimination reversal in hippocampally-lesioned rats. Physiology \& Behavior, 3 , 625-630.

Smith, M. L., MiLner, B. (1981). The role of the right hippocampus in the recall of spatial location. Neuropsychologia, 19, 781-793.

SQUiRE, L. R., \& COHEN, N. J. (1983). Human memory and amnesia. In R. F. Thompson \& J. L. McGaugh (Eds.), Handbook of behavioral neurobiology (pp. 3-64). New York: Plenum.

SutherLand, R. J., \& Rudy, J. W. (1989). Configural association theory: The role of the hippocampal formation in learning, memory, and amnesia. Psychobiology, 17, 129-144.

Weiskrantz, L., Warrington, E. K. (1975). The problem of the amnesic syndrome in man and animals. In R. L. Isaacson \& $\mathbf{K}$. H. Pribram (Eds.), The hippocampus: Neurophysiology and behavior (Vol. 2, pp. 411-428). New York: Plenum.

Winocur, G., \& Gilbert, M. (1984). The hippocampus, context, and information processing. Behavioral \& Neural Biology, 40, 27-43.

(Manuscript received July 22, 1989;

revision accepted for publication September 29, 1989.) 